\title{
Interhospital variability in health care-associated infections and payments after durable ventricular assist device implant among Medicare beneficiaries
}

Donald S. Likosky, PhD, ${ }^{a}$ Guangyu Yang, MS, ${ }^{\mathrm{b}}$ Min Zhang, PhD,${ }^{\mathrm{b}}$ Preeti N. Malani, MD, MSJ, Michael D. Fetters, MA, MPH, MD, ${ }^{\mathrm{d}}$ Raymond J. Strobel, MD, MS, ${ }^{\mathrm{e}}$ Carol E. Chenoweth, MSc, MD, ${ }^{\mathrm{c}}$ Hechuan Hou, MS, ${ }^{a}$ and Francis D. Pagani, MD, PhD, ${ }^{a}$ on behalf of the Michigan Congestive Heart Failure Investigators

\section{ABSTRACT}

Objective: The objective of this study was to investigate variations across hospitals in infection rates and associated costs, the latter reflected in 90-day Medicare payments. Despite high rates and expenditures of health care-associated infections associated with durable ventricular assist device implantation, few studies have examined interhospital variation and associated costs.

Methods: Clinical data on 8688 patients who received primary durable ventricular assist devices from July 2008 to July 2017 from the Society of Thoracic Surgeons Interagency Registry for Mechanically Assisted Circulatory Support (Intermacs) hospitals $(n=120)$ were merged with postimplantation 90-day Medicare claims. Terciles of hospital-specific, risk-adjusted infection rates per 100 patient-months were estimated using Intermacs and associated with Medicare payments (among 5440 Medicare beneficiaries). Primary outcomes included infections within 90 days of implantation and Medicare payments.

Results: There were 3982 infections identified among $27.8 \%$ (2417/8688) of patients developing an infection. The median (25th, 75th percentile) adjusted incidence of infections (per 100 patient-months) across hospitals was $14.3(9.3,19.5)$ and varied according to hospital (range, 0.0-35.6). Total Medicare payments from implantation to 90 days were $9.0 \%$ (absolute difference: $\$ 13,652$ ) greater in high versus low infection tercile hospitals $(P<.0001)$. The period between implantation to discharge accounted for $73.1 \%$ of the difference in payments during the implantation to 9o-day period across terciles.

Conclusions: Health care-associated infection rates post durable ventricular assist device implantation varied according to hospital and were associated with increased 9o-day Medicare expenditures. Interventions targeting preventing infections could improve the value of durable ventricular assist device support from the

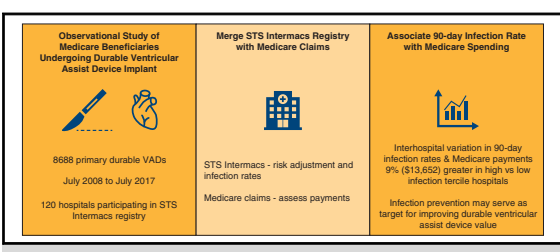

Durable implantation payments were $9 \%(\$ 13,652)$ greater in high versus low infection terciles.

CENTRAL MESSAGE

Post durable implantation 90day infection rates varied across hospitals (range, 0.0-35.6). Total 90-day payments were $9 \%$ $(\$ 13,652)$ greater in high versus low infection tercile hospitals.

\section{PERSPECTIVE}

Interhospital variation in HAl rates and Medicare payments after durable VAD implantation were evaluated. Median adjusted 9o-day HAl incidence varied according to hospital (range, 0.0-35.6). Total 90-day payments were $9.0 \%(\$ 13,652)$ greater in high versus low HAl tercile hospitals. HAI prevention could improve the value of durable VADs.

See Commentaries on pages 1569 and 1570. societal and hospital perspectives. (J Thorac Cardiovasc Surg 2022;164:1561-8)

Annually more than 250,000 patients in the United States with advanced heart failure could potentially benefit from durable ventricular assist device (VAD) support as a bridge

\footnotetext{
From the ${ }^{\mathrm{a}}$ Department of Cardiac Surgery, ${ }^{\mathrm{c}}$ Division of Infectious Diseases, Department of Medicine, and ${ }^{\mathrm{d} D e p a r t m e n t}$ of Family Medicine, Michigan Medicine, and ${ }^{\mathrm{b}}$ Department of Biostatistics, School of Public Health, University of Michigan, Ann Arbor, Mich; and ${ }^{\mathrm{e}}$ Department of Surgery, University of Virginia, Charlottesville, Va.

Donald S. Likosky received extramural support from the Agency for Healthcare Research and Quality (R01HS026003) and the National Heart, Lung, and Blood Institute (NHLBI, R01HL146619). Data for this study were provided, in part, by the Interagency Registry for Mechanically Assisted Circulatory Support (Intermacs), previously funded, in part, by the NHLBI under contract HHSN268201100025C. This study was undertaken before the acquisition of Intermacs by the Society of Thoracic Surgeons. Opinions expressed in this report do not represent those of Society of Thoracic Surgeons Intermacs, the NHLBI, the Centers for Medicare and Medicaid
}

to cardiac transplantation or as permanent support. ${ }^{1}$ However, broader adoption of VAD therapy for permanent use is hindered by the burden of complications including health

Services, the US Food and Drug Administration, the Agency for Healthcare Research and Quality, or the US Department of Health and Human Services.

Received for publication Nov 13, 2020; revisions received March 23, 2021; accepted for publication April 16, 2021; available ahead of print May 4, 2021.

Address for reprints: Donald S. Likosky, PhD, 1500 E Medical Center Dr, 5144 CVC, Department of Cardiac Surgery, University of Michigan, Ann Arbor, MI 48109 (E-mail: likosky@med.umich.edu).

0022-5223

Copyright (C) 2021 The Authors. Published by Elsevier Inc. on behalf of The American Association for Thoracic Surgery. This is an open access article under the CC BY-NC-ND license (http://creativecommons.org/licenses/by-nc-nd/4.0/).

https://doi.org/10.1016/j.jtcvs.2021.04.074 


\section{Abbreviations and Acronyms \\ $\mathrm{CABG}=$ coronary artery bypass grafting \\ $\mathrm{CI}=$ confidence interval \\ FDA $=$ US Food and Drug Administration \\ HAI = health care-associated infection \\ Intermacs $=$ Interagency Registry for Mechanically \\ Assisted Circulatory Support \\ $\mathrm{SD}=$ standard deviation \\ STS $=$ The Society of Thoracic Surgeons \\ $\mathrm{VAD}=$ ventricular assist device}

and Blood Institute). Details for hospital and patient linkages between these data sets have been reported. ${ }^{11}$

The study sample (Online Data Supplement) included patients who underwent primary, durable VAD implantation with a US Food and Drug Administration (FDA)-approved device between July 2008 and July 2017. Medicare suppression rules were enforced and represented in data tables with a symbol when there were fewer than 11 observations. ${ }^{12}$ Further exclusion criteria for payment data analyses are described in the Online Data Supplement.

Research use of these data was approved by Michigan Medicine's institutional review board (HUM00155687). Written informed consent for registrant participation in Intermacs was required until protocol v4.0 (February 27, 2014).

\section{Clinical Outcomes}

The primary outcome was a postoperative HAI reported to Intermacs using the registry's definition for infection adverse event ${ }^{13}$ (Online Data Supplement). Rates of HAIs were estimated through 90 days after implantation, because the risk of HAIs is greatest within this time frame. ${ }^{14}$

\section{Calculation of Medicare Payments}

Payments (inpatient, physician, other services) between 180 days before the index admission and post index utilization up to 90 days after the VAD implantation, conditional on patient survival, were analyzed (Online Data Supplement). Payments were price-standardized (adjusted for geographical differences in Medicare reimbursement rates) ${ }^{15}$ and inflationadjusted to 2017 dollars. ${ }^{16}$

\section{Patient Characteristics}

Intermacs and Medicare claims data were used to describe patient and clinical characteristics. Intermacs data ${ }^{13}$ (Online Data Supplement) were used to evaluate preoperative factors commonly used for risk adjustment. ${ }^{17-19}$

Data files were additionally used for the following purposes: (1) The American Hospital Association annual file was used to identify the implanting hospital's location, number of beds, and transplant status; (2) diagnosis codes within Medicare Part A claims were used to sum the total number of the Elixhauser comorbidity index comorbidities ${ }^{20,21}$; and (3) a hospital's overall VAD procedural volume was calculated on the basis of procedures identified in Medicare claims and the STS Intermacs. ${ }^{11}$

\section{Statistical Analysis}

Recurrent event analysis was used to examine HAI events. For each hospital, the crude incidence rate of HAI was estimated as the ratio of the number of HAI events over the total patient follow-up time. The indirect standardization method was used to estimate the risk-adjusted HAI incidence rate for each hospital. Specifically, the risk-adjusted rate was calculated as the overall incidence rate in the entire study population multiplied by the ratio of the observed number of HAIs over the expected number of HAIs for the patient mix at a certain hospital, if the hospital is performing as an average hospital. Candidate important risk factors (Online Data Supplement) were informed by their postulated clinical relevance by VAD experts and their previously identified effect on death. ${ }^{17-19}$

The expected number of HAIs was calculated on the basis of a 2-step strategy (Online Data Supplement). This strategy used the same approach leveraged for standardized hospitalization ratios. ${ }^{22}$

Hospitals were categorized into terciles on the basis of performance (ie, incident rates of HAIs). Terciles were computed for unadjusted and riskadjusted HAI rates. For each HAI tercile, patient characteristics, payments, and HAI outcomes (ie, mean and standard deviation [SD] and percentage, as appropriate) were evaluated and the cumulative mean number of HAIs were estimated. 
Data missingness was evaluated. In these instances, missing data were handled according to a pre-specified plan (Online Data Supplement).

Analyses were performed using SAS version 9.4 (SAS Institute, Inc, Cary, NC) and two-sided statistical tests $(\alpha=0.05)$. A link to the final analytical code is available in the Online Data Supplement.

\section{RESULTS}

\section{Study Population}

Characteristics that significantly differed across unadjusted HAI terciles are shown in Table 1. A more thorough list is provided in the Online Data Supplement.

The study included 8688 unique patients (120 hospitals) who received a durable VAD implantation and whose procedure was present in the Medicare claims and Intermacs datasets. Medicare beneficiaries represent on average $47.6 \%$ of a hospital's total Intermacs implantations. Additional details concerning hospital characteristics according to tercile of unadjusted (Online Data Supplement) and adjusted (Online Data Supplement) hospital HAI rates are available.

There were 3982 HAIs, with $27.8 \%$ of patients developing at least 1 HAI within 90 days of VAD implantation. Patients with an HAI had a mean of 1.6 (1.1) HAIs. The overall adjusted HAI incidence rate was 17.0 per 100 patientmonths (95\% confidence interval [CI], 16.5-17.6), although varied according to tercile. Adjusted rates of HAIs decreased from 24.3 in 2008 to 16.2 in 2017 ( $P$ trend $<.001)$.

Relative to the low tercile, patients in high tercile hospitals more often presented in Intermacs profile 1 or $2(51.2 \%$ vs $41.1 \%$ ) although were less likely to receive their VAD for destination therapy $(52.2 \%$ vs $61.5 \%)$. Although in many instances statistically significant differences (nominal $P$ values $<.05)$ were present, patients were qualitatively similar across tercile with regard to age, hemodynamic status, and key laboratory results. High versus low tercile hospitals had longer lengths of stay from implantation to discharge (27.4 [SD, 26.0] vs 23.6 [SD, 27.5]), had higher risk of reoperation for bleeding within 48 hours of implantation $(8.1 \%$ vs $5.4 \%)$, and were more likely to develop renal dysfunction (Online Data Supplement) within 90 days after implantation ( $12.7 \%$ vs $5.4 \%)$ and respiratory failure within 90 days after implantation $(22.0 \%$ vs $8.5 \%)$. The final Cox model coefficients and 95\% CIs are shown in the Online Data Supplement.

Overall survival through 90 days after implantation was $88.1 \%$ (95\% CI, 87.4\%-88.7\%), although varied according to adjusted HAI tercile: low, $88.9 \%(95 \%$ CI, $87.5 \%$ $90.1 \%$ ); middle, $88.8 \%$ (95\% CI, 87.6\%-89.9\%); and high, $87.0 \%$ (95\% CI, 85.8\%-88.0\%; $P=.03$; Online Data Supplement). The association between patient-level characteristics and outcomes across device- and non-device-related HAIs are presented in the Online Data Supplement.

Variability existed in the crude 90-day HAI rate across hospitals (Figure 1). The median (25th, 75th percentile) adjusted hospital HAI rate was $14.3(9.3,19.5)$ per 100 patient-months. The mean cumulative frequency of HAIs was 0.42 (95\% CI, 0.41-0.44; Figure 2). Risk-adjusted rates increased across terciles: low, 0.15 (95\% CI, 0.14-0.17), middle, 0.35 (95\% CI, 0.33-0.38), and high, 0.64 (95\% CI, 0.61-0.67).

Bacterial HAIs were the most common infection across unadjusted (Table 2, Online Data Supplement) and riskadjusted (Online Data Supplement) terciles. Rates of non-device-related HAIs were higher than device-related HAIs (15.6 vs 1.4), with both being more common in high versus low tercile hospitals: non-device-related, 24.3 versus 5.1; device-related, 1.9 versus 0.74 . Pulmonary infections were the most common HAI across each tercile.

Total mean Medicare payments were \$256,600 (SD, $\$ 93,120)$ and $\$ 12,497$ higher at high versus low tercile hospitals $(P<.001$; Online Data Supplement). Average payments during the 180 days before admission were $\$ 34,910$ (SD, \$30,269), from admission to implantation $\$ 63,432$ (SD, \$40,992), and from implantation to 90 days post implantation $\$ 158,258$ (SD, $\$ 77,131$ ). Most of the difference across terciles in total payments was attributed to the implantation to 90-day period (Online Data Supplement).

Payments between implantation to 90 days post implantation varied $\$ 13,652$ between high $(\$ 166,170$ [SD, $\$ 83,855]$ ) and low terciles $(\$ 152,518$ [SD, $\$ 69,716])$. Most $(83.7 \%)$ of the difference across high and low terciles for payments from implantation to 90 days was attributed to inpatient services $(43.3 \%$ and $40.4 \%$ attributed to diagnostic-related group and outlier payments, respectively; Online Data Supplement). The period between implantation to discharge accounted for $73.1 \%$ of the difference in payments during the implantation to 90-day period across terciles. Further stratification of payments across HAI subtypes is provided in the Online Data Supplement.

There was a significant correlation $(r=0.24)$ between a hospital's HAI rate and its average payments for the period from implantation to 90 days $(F=7.06 ; P=.01$; Online Data Supplement). However, after adjusting for baseline variables, this association was still positive but not significant $(P=.61)$.

\section{DISCUSSION}

This large, population-based study advances the literature concerning postimplantation HAIs. Specifically, significant interhospital variability was observed in: (1) the rate of HAIs and (2) payments for the period from 90 days after durable VAD implantation.

To our knowledge, this study is the first to report significant hospital variation in the rate and effect of HAIs after durable VAD implantation. Previous work in the setting of isolated coronary artery bypass grafting (CABG) surgery has documented large-scale differences in observed HAI rates. ${ }^{23,24}$ Shih and colleagues reported an $18.2 \%$ absolute difference in observed HAIs in contrast to a $2.8 \%$ predicted difference across hospitals performing CABG surgery in 
TABLE 1. Patient characteristics according to tercile of unadjusted 90-day HAI rate after durable VAD implantation

\begin{tabular}{|c|c|c|c|c|}
\hline & First (low) & Second (middle) & Third (high) & $P$ value \\
\hline HAI incidence rate $(95 \% \mathrm{CI})$ per 100 person-month & $5.8(5.2-6.5)$ & $13.9(13.1-14.8)$ & $26.2(25.2-27.3)$ & \\
\hline Patient $\mathrm{n}$ & 2101 & 2976 & 3611 & \\
\hline \multicolumn{5}{|l|}{ Demographic characteristics } \\
\hline Age, y & $66.2(57.4-71.0)$ & $65.2(55.8-70.0)$ & $65.2(56.2-69.3)$ & $<.0001$ \\
\hline Female sex & $406(19.4)$ & $627(21.1)$ & $678(18.8)$ & .05 \\
\hline Race & & & & $<.0001$ \\
\hline White & $1594(75.9)$ & $2059(69.2)$ & $2439(67.5)$ & \\
\hline African-American & $388(18.5)$ & $712(23.9)$ & $857(23.7)$ & \\
\hline Other & $119(5.7)$ & $205(6.9)$ & $315(8.7)$ & \\
\hline Hispanic & $125(6.0)$ & $130(4.4)$ & $253(7.1)$ & $<.0001$ \\
\hline \multicolumn{5}{|l|}{ Indication } \\
\hline Device strategy* & & & & $<.0001$ \\
\hline Group 1 & $583(27.8)$ & $972(32.7)$ & $1389(38.5)$ & \\
\hline Group 2 & $225(10.7)$ & $373(12.5)$ & $338(9.4)$ & \\
\hline Group 3 & $1293(61.5)$ & $1631(54.8)$ & $1884(52.2)$ & \\
\hline Device & & & & $<.0001$ \\
\hline HeartMate II LVAS & $1897(90.3)$ & $2504(84.1)$ & $2913(80.7)$ & \\
\hline HeartWare HVAD & $\dagger$ & $\dagger$ & $639(17.7)$ & \\
\hline Other & $\dagger$ & $\dagger$ & $59(1.6)$ & \\
\hline \multicolumn{5}{|l|}{ Patient characteristics } \\
\hline Intermacs profile & & & & $<.0001$ \\
\hline Profile 1 & $185(8.8)$ & $332(11.2)$ & $482(13.4)$ & \\
\hline Profile 2 & $678(32.3)$ & $1095(36.8)$ & $1365(37.8)$ & \\
\hline Profile 3 & $827(39.4)$ & 999 (33.6) & $1067(29.6)$ & \\
\hline Profile $4-7$ & $411(19.6)$ & $550(18.5)$ & $697(19.3)$ & \\
\hline New York Heart Association Class & & & & $<.0001$ \\
\hline I-II & $19(0.9)$ & $22(0.7)$ & $19(0.5)$ & \\
\hline III & $423(20.1)$ & $503(16.9)$ & $524(14.5)$ & \\
\hline IV & $1587(75.5)$ & $2245(75.4)$ & $2868(79.4)$ & \\
\hline Missing & $72(3.4)$ & $206(6.9)$ & $200(5.5)$ & \\
\hline History of cardiac operation & $825(39.3)$ & $1122(37.7)$ & $1508(41.8)$ & $<.01$ \\
\hline \multicolumn{5}{|l|}{ Hemodynamics } \\
\hline Systolic blood pressure, $\mathrm{mm} \mathrm{Hg}$ & $106.0(97.0-117.0)$ & $106.0(96.0-117.0)$ & $104.0(95.0-115.0)$ & $<.0001$ \\
\hline Diastolic blood pressure, $\mathrm{mm} \mathrm{Hg}$ & $64.0(57.0-71.0)$ & $65.0(57.0-72.0)$ & $63.0(56.0-71.0)$ & $<.0001$ \\
\hline Central venous pressure, $\mathrm{mm} \mathrm{Hg}$ & $11.0(7.0-16.0)$ & $12.0(7.0-17.0)$ & $11.0(7.0-16.0)$ & $<.01$ \\
\hline Pulmonary artery systolic pressure, $\mathrm{mm} \mathrm{Hg}$ & $48.0(39.0-58.0)$ & $51.0(41.0-62.0)$ & $51.0(41.0-61.0)$ & $<.0001$ \\
\hline Pulmonary artery diastolic pressure, $\mathrm{mm} \mathrm{Hg}$ & $23.0(18.0-29.0)$ & $25.0(19.0-31.0)$ & $25.0(19.0-30.0)$ & $<.0001$ \\
\hline Pulmonary capillary wedge pressure, $\mathrm{mm} \mathrm{Hg}$ & $24.0(18.0-30.0)$ & $24.0(19.0-30.0)$ & $24.0(18.0-30.0)$ & .04 \\
\hline \multicolumn{5}{|l|}{ Laboratory studies } \\
\hline Serum creatinine, $\mathrm{mg} / \mathrm{dL}$ & $1.3(1.1-1.7)$ & $1.3(1.0-1.7)$ & $1.4(1.1-1.8)$ & $<.0001$ \\
\hline Blood urea nitrogen, $\mathrm{mg} / \mathrm{dL}$ & $27.0(19.0-38.0)$ & $26.0(18.0-37.0)$ & $27.0(19.0-40.0)$ & $<.0001$ \\
\hline Hemoglobin, g/dL & $11.3(10.0-12.8)$ & $11.2(9.9-12.6)$ & $11.2(9.8-12.6)$ & .01 \\
\hline Albumin, $\mathrm{g} / \mathrm{dL}$ & $3.4(3.0-3.8)$ & $3.4(3.0-3.8)$ & $3.5(3.1-3.9)$ & $<.0001$ \\
\hline Alanine aminotransferase, $\mathrm{U} / \mathrm{L}$ & $26.0(17.0-41.0)$ & $28.0(18.0-45.0)$ & $26.0(18.0-45.0)$ & $<.01$ \\
\hline Aspartate aminotransferase, U/L & $27.0(20.0-39.0)$ & $29.0(22.0-42.0)$ & $28.0(21.0-42.0)$ & $<.0001$ \\
\hline International normalized ratio & $1.2(1.1-1.3)$ & $1.2(1.1-1.4)$ & $1.2(1.1-1.4)$ & $<.0001$ \\
\hline \multicolumn{5}{|l|}{ Procedural details } \\
\hline LVAD with subsequent RVAD within $90 \mathrm{~d}$ after implantation, $\mathrm{n}(\%)$ & $16(0.8)$ & $33(1.1)$ & $70(1.9)$ & $<.001$ \\
\hline \multicolumn{5}{|l|}{ Interventions at index hospitalization } \\
\hline Intravenous inotropes & $1760(84.1)$ & $2422(81.7)$ & $2797(77.7)$ & $<.0001$ \\
\hline Intra-aortic balloon pump within $48 \mathrm{~h}$ & $352(16.8)$ & $644(21.6)$ & $888(24.6)$ & $<.0001$ \\
\hline Extracorporeal membrane oxygenation within $48 \mathrm{~h}$ & $20(1.0)$ & $52(1.8)$ & $70(1.9)$ & .02 \\
\hline Modifier temporary circulatory support & $266(16.7)$ & $630(27.2)$ & $753(27.1)$ & $<.0001$ \\
\hline
\end{tabular}


TABLE 1. Continued

\begin{tabular}{|c|c|c|c|c|}
\hline & First (low) & Second (middle) & Third (high) & $P$ value \\
\hline Dialysis or continuous venovenous ultrafiltration within $48 \mathrm{~h}$ & $19(0.9)$ & $52(1.8)$ & $86(2.4)$ & $<.001$ \\
\hline Diuretic type (bumetamide) & $324(16.6)$ & $331(11.8)$ & $531(15.9)$ & $<.0001$ \\
\hline \multicolumn{5}{|l|}{ Outcomes } \\
\hline Length of stay, implantation to discharge, $\mathrm{d}$ & $18.0(13.0-26.0)$ & $18.0(14.0-27.0)$ & $21.0(15.0-32.0)$ & $<.0001$ \\
\hline Acute care duration, $\mathrm{d}$ & $7.0(5.0-12.0)$ & $7.0(5.0-13.0)$ & $7.0(5.0-14.0)$ & .9986 \\
\hline Intermediate/step-down care duration, $\mathrm{d}$ & $9.0(6.0-13.0)$ & $9.0(6.0-14.0)$ & $11.0(7.0-17.0)$ & $<.0001$ \\
\hline Discharge location $\ddagger$ & & & & $<.0001$ \\
\hline Home & $1296(61.7)$ & $1849(62.1)$ & $2035(56.4)$ & \\
\hline Nursing home/assisted care & $29(1.4)$ & $63(2.1)$ & $68(1.9)$ & \\
\hline Rehabilitation facility & $504(24.0)$ & $728(24.5)$ & $980(27.1)$ & \\
\hline Other (Hospice, another hospital, other facility, unknown) & $14(0.7)$ & $36(1.2)$ & $45(1.3)$ & \\
\hline Missing & $258(12.3)$ & $300(10.1)$ & $483(13.4)$ & \\
\hline Reoperation for bleeding within $48 \mathrm{~h}$ of implantation & $66(5.4)$ & $92(5.1)$ & $182(8.1)$ & $<.001$ \\
\hline Renal dysfunction within $90 \mathrm{~d}$ after implantation & $114(5.4)$ & $272(9.1)$ & $460(12.7)$ & $<.0001$ \\
\hline Respiratory failure within $90 \mathrm{~d}$ after implantation & $178(8.5)$ & $474(15.9)$ & $794(22.0)$ & $<.0001$ \\
\hline Stroke within $90 \mathrm{~d}$ after implantation & $122(5.8)$ & $189(6.4)$ & $268(7.4)$ & .04 \\
\hline Death within $90 \mathrm{~d}$ after implantation & $230(11.0)$ & $320(10.8)$ & $477(13.2)$ & $<.01$ \\
\hline
\end{tabular}

Continuous variables are given as median (IQR) and categorical variables as $n(\%)$, except where otherwise noted. $P$ values are calculated using the Kruskal-Wallis test (continuous variables) and Pearson $\chi^{2}$ test (categorical variables). The HeartMate II LVAS is from Abbott Laboratories (Abbott Park, Ill). The HeartWare HVAD is from Medtronic (Dublin, Ireland). HAI, Health care-associated infection; VAD, ventricular assist device; $C I$, confidence interval; LVAS, left ventricular assist system; Intermacs, Interagency Registry for Mechanically Assisted Circulatory Support; $L V A D$, left ventricular assist device; $R V A D$, right ventricular assist device. *For device strategy, group 1 includes bridge to transplant (listed) + bridge to transplant (likely) + bridge to recovery; group 2 includes bridge to transplant (moderately likely) + bridge to transplant (unlikely) + rescue therapy + other; and group 3 includes destination therapy. $\dagger$ Data cells with $<11$ beneficiaries have been replaced with a " $\dagger$ " symbol in accordance with the Centers for Medicare and Medicaid Services suppression policy. ‡Among patients discharged alive.

Michigan. ${ }^{24}$ However, an analysis of 998 hospitals suggested that only $2 \%$ of hospital variation in CABG HAIs is accounted for using traditional risk factors. ${ }^{25}$ In this present analysis of VAD devices, adjusted 90-day HAI rates varied $35.6 \%$ in absolute terms across hospitals.

Further, this study is the first to our knowledge to link interhospital HAI variability to Medicare payments, thereby leveraging the strengths inherent in the claims and clinical registry databases. Findings from this study reinforce the importance (from a value standpoint) of identifying and disseminating optimal HAI preventive practices at high performing institutions because: (1) patients at high versus low

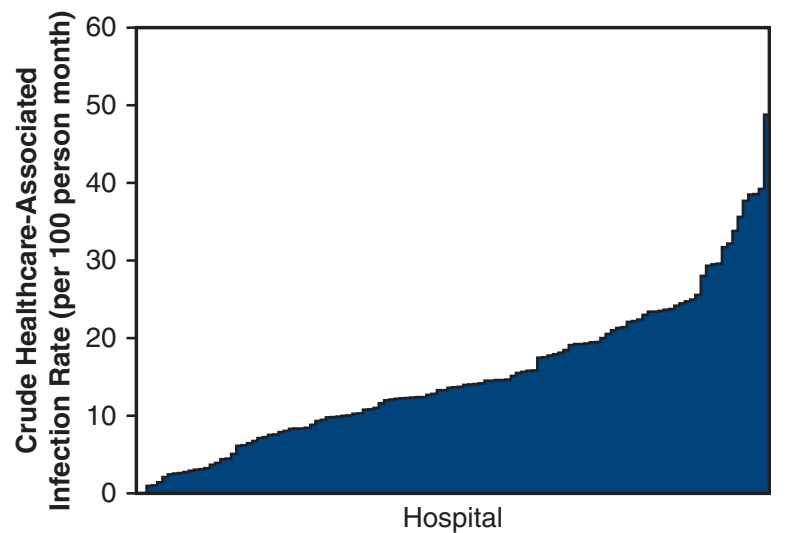

FIGURE 1. Crude 90-day hospital health care-associated infection rate (per 100 patient-months) after durable ventricular assist device implantation. Distribution of crude 90-day hospital infection rates.
HAI hospitals were more likely to have higher payments between the implantation to 90-day period, and (2) the implantation to discharge period accounted for most of the difference in 90-day payments across terciles.

These findings have important implications for reducing VAD-associated HAIs. Previous studies have established the effect of targeted interventions to reduce HAIs in other cardiac surgical settings. Likosky, using a collaborative learning intervention (ie, quarterly data feedback reporting, site visits, and centralized quality improvement support), reported significant reductions in post-CABG pneumonia relative to hospitals receiving quarterly STS feedback reports. ${ }^{26}$ However, CABGspecific HAI prevention strategies might not apply given: (2) VAD represents a large cardiovascular implantable electrical device, (2) unique surgical features (eg, percutaneous lead), and (3) frequent hemodynamic instability at implantation. The STS is well positioned to advance VAD-specific HAI benchmarking and evaluate HAIpreventive practices at low- and high-performance outlier hospitals, an initiative currently under way through a grant from the Agency for Healthcare Research and Quality. ${ }^{27}$

Several limitations exist in this descriptive study. First, this Intermacs cohort does not include all durable VADs implanted in the United States. ${ }^{11}$ However, Intermacs does include nearly all FDA-approved implanted devices. Second, the dataset used for this study lacks important specificity regarding infections 

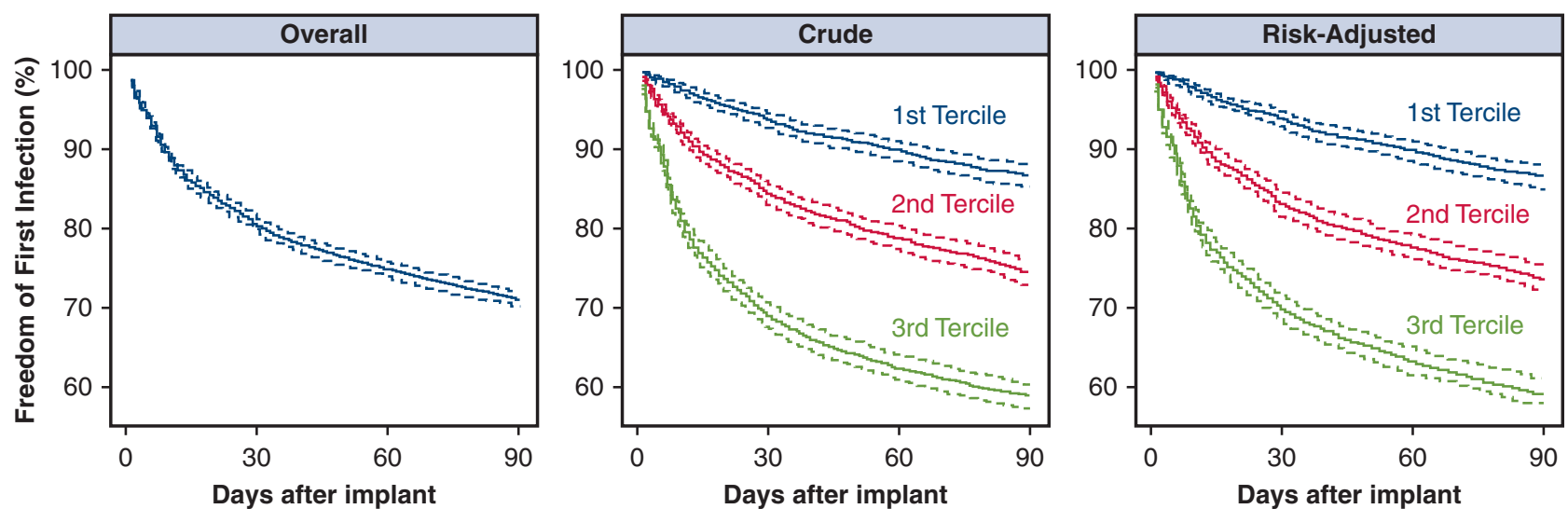

\begin{tabular}{|l|c|c|c|c|}
\hline Cohort & 0 & 30 & 60 & 90 \\
\hline Overall & 8688 & 8067 & 7700 & 7338 \\
\hline
\end{tabular}

\begin{tabular}{|l|c|c|c|c|}
\hline Cohort & 0 & 30 & 60 & 90 \\
\hline $1^{\text {st }}$ Tercile & 2101 & 1955 & 1878 & 1804 \\
\hline $2^{\text {nd }}$ Tercile & 2976 & 2792 & 2667 & 2538 \\
\hline $3^{\text {rd }}$ Tercile & 3611 & 3320 & 3155 & 2996 \\
\hline
\end{tabular}

\begin{tabular}{|c|c|c|c|c}
\hline Cohort & 0 & 30 & 60 & 90 \\
\hline $1^{\text {st }}$ Tercile & 2199 & 2044 & 1958 & 1878 \\
\hline $2^{\text {nd }}$ Tercile & 2847 & 2665 & 2551 & 2429 \\
\hline $3^{\text {rd }}$ Tercile & 3642 & 3358 & 3191 & 3031 \\
\hline
\end{tabular}

FIGURE 2. Mean crude and risk-adjusted cumulative frequency of 90-day hospital health care-associated infection rate after durable ventricular assist device implantation. Overall (left panel), crude (center panel), and risk-adjusted (right panel) cumulative frequency of 90-day hospital infection rates, along with $95 \%$ confidence intervals. The center and right panels are stratified according to tercile of hospital infection rates.

TABLE 2. Ninety-day HAI rates according to tercile of crude 90-day HAI rate after durable VAD implantation

\begin{tabular}{|c|c|c|c|c|c|}
\hline & \multirow[b]{2}{*}{ Overall $(n=8688)$} & \multicolumn{4}{|c|}{ Tercile of unadjusted HAI rate (per 100 patient-months)* } \\
\hline & & $\begin{array}{c}\text { First } \\
(\text { low; } n=2101)\end{array}$ & $\begin{array}{c}\text { Second } \\
\text { (middle; } n=2976 \text { ) }\end{array}$ & $\begin{array}{c}\text { Third } \\
\text { (high; } \mathbf{n}=\mathbf{3 6 1 1})\end{array}$ & $\boldsymbol{P}$ value $\dagger$ \\
\hline \multicolumn{6}{|l|}{ Infection type } \\
\hline Bacterial & 14.2 & 4.8 & 11.9 & 21.8 & $<.0001$ \\
\hline Fungal & 1.2 & 0.3 & 0.7 & 2.1 & $<.0001$ \\
\hline Protozoan & 0.03 & 0.02 & 0.1 & 0.03 & .58 \\
\hline Viral & 0.3 & 0.1 & 0.3 & 0.4 & $<.001$ \\
\hline Unknown & 1.3 & 0.7 & 1.1 & 1.9 & $<.0001$ \\
\hline \multicolumn{6}{|l|}{ Device or non-device-related infections } \\
\hline Non-device-related only & 15.6 & 5.1 & 12.6 & 24.3 & $<.0001$ \\
\hline Device-related only & 1.4 & 0.7 & 1.3 & 1.9 & $<.0001$ \\
\hline Overall & 17.0 & 5.8 & 13.9 & 26.2 & $<.0001$ \\
\hline \multicolumn{6}{|l|}{ Location of infection } \\
\hline Pulmonary & 4.6 & 1.3 & 3.6 & 7.4 & $<.0001$ \\
\hline Urine & 3.4 & 1.2 & 2.8 & 5.3 & $<.0001$ \\
\hline Blood cultures, positive & 2.7 & 0.8 & 2.1 & 4.3 & $<.0001$ \\
\hline Other & 1.9 & 0.6 & 1.4 & 3.0 & $<.0001$ \\
\hline Gastrointestinal & 1.2 & 0.5 & 1.0 & 1.8 & $<.0001$ \\
\hline Pump-related: drive line or percutaneous lead & 1.0 & 0.5 & 1.0 & 1.4 & $<.0001$ \\
\hline Mediastinum & 0.6 & 0.3 & 0.6 & 0.7 & $<.001$ \\
\hline Line sepsis & 0.4 & 0.2 & 0.4 & 0.6 & $<.001$ \\
\hline Unknown & 0.5 & 0.2 & 0.4 & 0.7 & $<.0001$ \\
\hline Peripheral wound & 0.4 & 0.1 & 0.3 & 0.6 & $<.0001$ \\
\hline Pump-related: pump pocket & 0.3 & 0.2 & 0.3 & 0.4 & .27 \\
\hline Pump-related: exit cannula & 0.04 & 0.04 & 0.01 & 0.1 & .12 \\
\hline Pump-related: pump interior & 0.03 & 0.0 & 0.01 & 0.1 & .03 \\
\hline
\end{tabular}

$H A I$, Health care-associated infection; $V A D$, ventricular assist device. *Patients could have $>1$ infection. $\dagger P$ value calculated using the Wald test. 


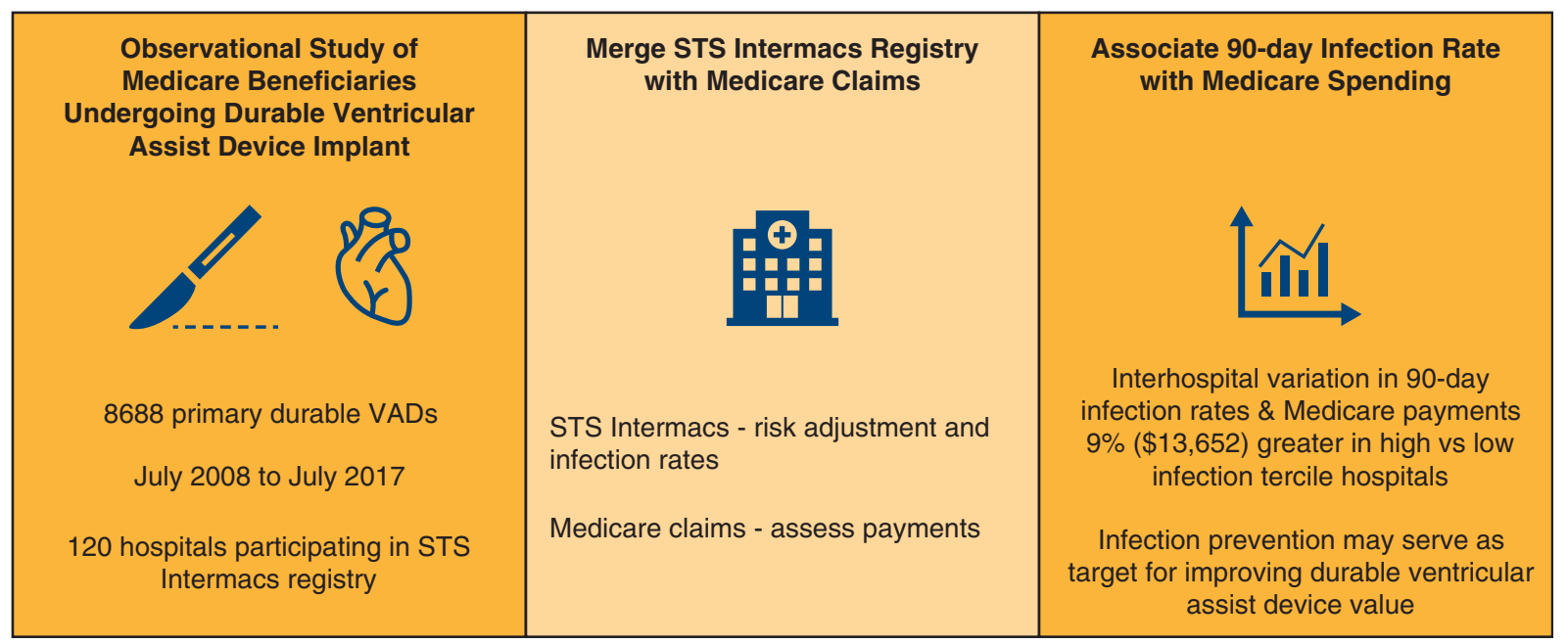

FIGURE 3. Study design, results, and implications. Adjusted incidence of infections varied by hospital, and total Medicare payments from implant to 90-days were $9.0 \%$ greater in high- versus low-infection tercile hospitals. Infection prevention could improve the value of durable ventricular assist devices.

(eg, specific infectious organisms, infection prevention practices) and might under-report the true number of HAIs; however, Intermacs-submitting hospitals leveraged trained data coordinators who used strict definitions to guide HAI determination and the database undergoes routine audits. Importantly, HAI rates reported in this study are very similar to other published HAI rates documented from recent randomized clinical trials of durable VADs. ${ }^{5-8}$ Third, pre- and postprocedure inpatient payment estimates assume a constant daily payment rate that might not be reflective of all patients' experiences; nonetheless, price standardization methods account for differences attributed to local and regional practice differences. Fourth, unmeasured confounding might persist. To mitigate its effect, commonly cited patient-level factors and hospital variation were accounted for through hierarchical modeling. Although these data reflect experiences through July 2017, this cohort represents to our knowledge the largest, most contemporaneous VAD experience evaluating HAIs among Medicare beneficiaries. Comparable survival at 90-days and major HAI rates between this report and The Multicenter Study of MagLev Technology in Patients Undergoing Mechanical Circulatory Support Therapy With HeartMate 3 (MOMENTUM 3) experience ${ }^{8}$ support the generalizability of our findings.

Post VAD implantation HAIs are common and vary in rate across hospitals. Patients cared for at hospitals with higher HAI rates had greater associated index admission resource utilization, postoperative morbidity, and expenditures. The current findings suggest that a portion of these HAIs might be preventable because of the $36.5 \%$ absolute difference in adjusted hospital HAI rates (Figure 3). Ongoing research on detailed hospital- and unit-level practices could provide further insight into determinants of HAI variation. ${ }^{27}$ Large-scale improvements in the quality, safety, and expenditures associated with VAD care might be realized through the evaluation and subsequent dissemination of HAI prevention best practices.

\section{Conflict of Interest Statement}

Francis D. Pagani is a member of the scientific advisory board of FineHeart, Inc, member of the Data Safety Monitoring Board for Carmat, Inc, member of the Data Safety Monitoring Board for the National Heart, Blood, and Lung Institute PumpKIN clinical trial, and Chair of The STS Intermacs Task Force. All other authors reported no conflicts of interest.

The Journal policy requires editors and reviewers to disclose conflicts of interest and to decline handling or reviewing manuscripts for which they may have a conflict of interest. The editors and reviewers of this article have no conflicts of interest.

The authors thank Daniel Gottlieb, Keith Aaronson, Lourdes Cabrera, Qixing Liang, Michael Thompson, and Xiaoting Wu for their contributions; Susan Meyers for assistance with data queries; and the Michigan Congestive Heart Failure Investigators: Donald S. Likosky, PhD, Francis D. Pagani, MD, PhD, Ashraf Shaaban Abdel Aziz Abou El Ela, MB, BCH, Paul C. Tang, MD, PhD, Michael P. Thompson, PhD, Keith Aaronson, MD, MS, Supriya Shore, MBBS, Thomas Cascino, MD, MSc, Katherine B. Salciccioli, MD, Min Zhang, PhD, Jeffrey S. McCullough, 
PhD, Michelle Hou, MS, Allison M. Janda, MD, Michael R. Mathis, MD, Tessa M. F. Watt, MD, MSc, Michael J. Pienta, MD, MS, Alexander Brescia, MD, MSc, Austin Airhart, Daniel Liesman, and Khalil Nassar.

\section{References}

1. Miller LW. Left ventricular assist devices are underutilized. Circulation. 2011; 123:1552-8; discussion: 1558 .

2. Hannan MM, Xie R, Cowger J, Schueler S, By TD, Dipchand AI, et al. Epidemiology of infection in mechanical circulatory support: a global analysis from the ISHLT mechanically assisted circulatory support registry. $J$ Heart Lung Transplant. 2019;38:364-73.

3. Kirklin JK, Naftel DC, Pagani FD, Kormos RL, Stevenson LW, Blume ED, et al Seventh INTERMACS annual report: 15,000 patients and counting. J Heart Lung Transplant. 2015;34:1495-504.

4. Kirklin JK, Naftel DC, Kormos RL, Stevenson LW, Pagani FD, Miller MA, et al Fifth INTERMACS annual report: risk factor analysis from more than 6,000 mechanical circulatory support patients. J Heart Lung Transplant. 2013;32:141-56.

5. Milano CA, Rogers JG, Tatooles AJ, Bhat G, Slaughter MS, Birks EJ, et al. HVAD: the ENDURANCE supplemental trial. JACC Heart Fail. 2018;6: 792-802.

6. Rogers JG, Pagani FD, Tatooles AJ, Bhat G, Slaughter MS, Birks EJ, et al. Intrapericardial left ventricular assist device for advanced heart failure. $N$ Engl J Med. 2017;376:451-60.

7. Mehra MR, Uriel N, Naka Y, Cleveland JC Jr, Yuzefpolskaya M, Salerno CT, et al. A fully magnetically levitated left ventricular assist device - final report. N Engl J Med. 2019;380:1618-27.

8. Patel CB, Blue L, Cagliostro B, Bailey SH, Entwistle JW, John R, et al. Left ventricular assist systems and infection-related outcomes: a comprehensive analysis of the MOMENTUM 3 trial. J Heart Lung Transplant. 2020;39:774-81.

9. Tattevin P, Flecher E, Auffrer V, Leclercq C, Boule S, Vincentelli A, et al. Risk factors and prognostic impact of left ventricular assist device-associated infections. Am Heart J. 2019;214:69-76.

10. O'Horo JC, Abu Saleh OM, Stulak JM, Wilhelm MP, Baddour LM, Rizwan Sohail M. Left ventricular assist device infections: a systematic review. ASAIO J. 2018;64:287-94.

11. Liang Q, Ward S, Pagani FD, Sinha SS, Zhang M, Kormos R, et al. Linkage of Medicare records to the interagency registry of mechanically assisted circulatory support. Ann Thorac Surg. 2018;105:1397-402.

12. ResDAC : Research Data Assistance Center. CMS cell size suppression policy. Available at: https://www.resdac.org/articles/cms-cell-size-suppression-policy. Accessed September 27, 2019.

13. The University of Alabama at Birmingham. STS Intermacs Database. Available at: https://www.uab.edu/medicine/intermacs/intermacs-documents. Accessed January 4, 2019.

14. Kirklan JK, Pagani FD, Kormos RL, Stevenson LW, Blume ED, Myers SL, et al. Eighth annual INTERMACS report: special focus on framing the impact of adverse events. J Heart Lung Transplant. 2017;36:1080-6.
15. Gottlieb DJ, Zhou W, Song Y, Andrews KG, Skinner JS, Sutherland JM. Prices don't drive regional Medicare spending variations. Health Aff (Millwood). 2010;29:537-43.

16. Council of Economic Advisers. Table B-5. Chain-type price indexes for gross domestic product, 1968-2018. Available at: https://www.govinfo.gov/content/ pkg/ERP-2019/pdf/ERP-2019-table5.pdf. Accessed May 24, 2021.

17. Kormos RL, Cowger J, Pagani FD, Teuteberg JJ, Goldstein DJ, Jacobs JP, et al. The Society of Thoracic Surgeons Intermacs database annual report: evolving indications, outcomes, and scientific partnerships. J Heart Lung Transplant. 2019; 38:114-26

18. Teuteberg JJ, Cleveland JC Jr, Cowger J, Higgins RS, Goldstein DJ, Keebler M, et al. The Society of Thoracic Surgeons Intermacs 2019 annual report: the changing landscape of devices and indications. Ann Thorac Surg. 2020;109:649-60.

19. Molina EJ, Shah P, Kiernan MS, Cornwell WK III, Copeland H, Takeda K, et al. The Society of Thoracic Surgeons Intermacs 2020 annual report. Ann Thorac Surg. 2021;111:778-92.

20. Krumholz HM, Wang Y, Mattera JA, Wang Y, Han LF, Ingber MJ, et al. An administrative claims model suitable for profiling hospital performance based on 30-day mortality rates among patients with heart failure. Circulation. 2006; 113:1693-701.

21. Keenan PS, Nommand SLT, Lin Z, Drye EE, Bhat KR, Ross JS, et al. An administrative claims measure suitable for profiling hospital performance on the basis of 30-day all-cause readmission rates among patients with heart failure. Circ Cardiovasc Qual Outcomes. 2008;1:29-37.

22. University of Michigan Kidney Epidemiology and Cost Center. Report for the standardized hospitalization ratio. Available at: https://www.cms.gov/Medi care/Quality-Initiatives-Patient-Assessment-Instruments/ESRDQIP/Downloads/ SHR-Methodology-Report.pdf. Accessed May 25, 2021.

23. Likosky DS, Wallace AS, Prager RL, Jacobs JP, Zhang M, Harrington SD, et al. Sources of variation in hospital-level infection rates after coronary artery bypass grafting: an analysis of the Society of Thoracic Surgeons adult heart surgery database. Ann Thorac Surg. 2015;100:1570-5; discussion: 1575-6.

24. Shih T, Zhang M, Kommareddi M, Boeve TJ, Harrington SD, Holmes RJ, et al. Center-level variation in infection rates after coronary artery bypass grafting. Circ Cardiovasc Qual Outcomes. 2014;7:567-73.

25. Brescia AA, Rankin JS, Cyr DD, Jacobs JP, Prager RL, Zhang M, et al. Determinants of variation in pneumonia rates after coronary artery bypass grafting. Ann Thorac Surg. 2018;105:513-20.

26. Likosky DS. Collaborative quality improvement reduces postoperative pneumonia after isolated coronary artery bypass grafting surgery. Circ Cardiovasc Qual Outcomes. 2018;11:e004756.

27. Chandanabhununa PP, Fetters MD, Pagani FD, Malani PN, Hollingsworth JM, Funk RJ, et al. Understanding and addressing variation in health care-associated infections after durable ventricular assist device therapy: protocol for a mixed methods study. JMIR Res Protoc. 2020;9:e14701.

Key Words: ventricular assist device, infection, expenditure 